\title{
In Conversation with Kenneth Rawnsley: Part II
}

The following is the second part of Brian Barraclough's interview with Professor Rawnsley. Part I appeared in the January Bulletin.

BB Perhaps we can turn now to the Royal College. Were you involved with the foundation of the College?

KR Not really. I was a member of the Royal MedicoPsychological Association Council, but I wasn't in the inner circles if I can put it that way. I didn't see the inside machinations, but I was aware of some fierce infighting going on between different factions. Some people were much opposed to any change in the RMPA, or if there was a change they thought it should be to a Faculty of the Royal College of Physicians of London. Others were sure there should be a Royal College of Psychiatrists. There was acrimonious debate. Many people felt the RMPA 'establishment' had been for long an inward-looking and self-perpetuating oligarchy. The Council and the Officers were people selecting themselves or were being selected by a small coterie. The President was, in effect, elected by the Council as were the Officers. There was much dissatisfaction. I remember one or two quarterly meetings of the RMPA when things were pretty rough. Eventually a referendum of the Membership gave the clear result in favour of a Royal College. After that there was a long series of discussions with the Privy Council for the Supplementary Charter.

BB Do you understand why, constitutionally, it should be the Privy Council as opposed to Parliament? It seems to be a thoroughly unrepresentative alternative system of government.

KR The Privy Council represents the Queen. The Queen promulgates the Charter on the advice of her Privy Council. Somebody once said negotiating with the Privy Council was like trying to argue with a black man in a coal cellar at midnight to find the right questions to ask in the first instance. That's the system, that's the way it operates,

BB I can see you are a man who believes in working with systems.

KR Oh yes, I do.

BB Not to change them.

KR No. It would be a waste of time to try and change this particular system. I believe there were one or two bodies in the medical establishment very much against a College of Psychiatrists who put in a number of oars to prevent it.
BB You're not going to name them?

KR The London College of Physicians was one of them. They were keen on a Faculty of Psychiatrists within their College.

BB And the other Royal Colleges?

KR The surgeons would see it as an irrelevance. The Royal College of General Practitioners were supportive and welcoming when our College was established.

BB Were you involved in the negotiations?

KR No. I was a member of the RMPA Council but not privy, except to reports from those negotiating, like Ben Monro, secretary of the RMPA, a key figure.

We became a College, and got our Supplementary Charter. Then it was agreed we would go straight ahead preparing for the Membership examination.

BB Before the election of the Officers of the new College?

KR Yes. There was a transitional period, and then the Officers were elected. I was elected Dean.

BB How did that happen? There had been no Dean in the RMPA.

KR The RMPA equivalent was the Registrar. William Sargant had been Registrar for years and years. Ben Monro was the Secretary of the RMPA for a long time. Then there was a President who served for a year.

BB So he had no power.

KR By the time he had decided what was to be done he was off.

BB Martin Cuthbert was the last President.

KR Martin was both last President of the RMPA and transitional President. Then Martin Roth was elected as the first President of the College, by general election. This was one of the key changes in the Constitution. The Officers, with the exception of the vice-Presidents, were to be elected by the membership.

BB Roth would not have been the first President otherwise.

KR I'm sure that's right. But he was clearly elected.

BB With the publication of the votes, a practice which has ceased.

KR The Presidential votes are still published aren't they? BB I haven't seen them. I understand they are not to be published any more. I regard this as a retrograde step don't you? It is a political office and you stand in public to be elected. 
KR You think it should be published for all the Officers?

BB I do. Why not?

KR It can be embarrassing if someone has attracted say three votes.

BB They will think twice before standing again. How did you come to be nominated as Dean?

KR I was a member of Council and was a Council nominee. Some people are nominated by Council and others by members.

BB Martin Roth was not nominated by Council.

KR No, he wasn't. He was nominated by a group of members. Not that it matters one way or the other because that doesn't appear on the ballot paper. Perhaps people thought I was interested in education. Anyway I was elected and immediately found myself in the middle of all kinds of strong currents of emotion and pressures.

BB What was the Dean's job?

KR The Dean is the chief academic officer of the College. His job is to oversee the examinations of the College. I know there is a Chief Examiner, but the Dean's job is ultimately to ensure the exam operates. It's the Dean's job to ensure the educational and training functions of the College are in good order. One of the first things I had to do was to get cracking on a system for approving the training programmes throughout the UK and Eire.

BB Was that your idea?

KR No. The idea had come out of the RMPA Committees. I had to implement it.

BB There must have been something existing before that.

KR No.

BB There was for the Conjoint DPM.

KR Yes. But that wasn't anything to do with our College.

BB I realise that, but there was a pre-existing system whereby certain hospitals were approved for training.

KR Yes, that's right but there was no inspection. It was a bit of a nonsense really.

BB Yes and no. The idea was there.

KR Yes. Anyway I had to get on with the business of constructing what became the Approval Exercise, from scratch.

BB Nothing had ever been attempted on this scale by any College?

KR No, nothing. There were inspections of a kind at registrar and SHO levels by some Colleges, but nothing on the scale we attempted. We devised a scheme and did four pilot visits. I took part in them. On that experience we drew up a plan for the United Kingdom and for the Republic of Ireland, because the College writ extends through the British Isles.

BB Isn't that extraordinary?

KR Yes. I had to decide how to work it and which Divisions of the College would visit other Divisions.
I tried to do it in such a way that if, let's say, Scotland was approving Ireland, then at no time would Ireland approve Scotland. There had to be a cunning Latin Square design. It was a bit hairy to begin with. First of all on the question of who was going to pay for it, travelling and so on. We got the money through the Health Service eventually.

BB Because the DHSS was in favour?

KR Yes. To raise standards. We were approving hospitals as suitable for preparation for the Membership exam. Without a Membership exam we would have had no reason to go around the country looking at these places. So the Membership exam was a good excuse for the Approval Exercise.

BB Were there criteria?

KR Yes a list of criteria refined over the years.

BB Applied uniformly?

KR Yes, because of the way the thing was designed. We had a Convenor from each of the College Regional Divisions who took the main initiative in carrying out the visit. They recruited people from a panel to go on visits. Reports were prepared. Then the Convenors, ten of them altogether, one for each Division, met in a body called the Central Approval Panel of which I as Dean was chairman. This set the standards. The Court of Electors ratified the decisions of the Central Approval Panel. The whole thing went far more smoothly than I ever dared to hope and nowhere more so than in Eire, interestingly enough, where people were quite uncertain how it was going to work. There were good centres in the Republic but some difficult areas too. We never had any problems there and were always welcome.

The Approval Exercise involved a great many people looking at other people's training programmes. In this way good ideas were communicated in both directions, for the people going around doing the visits and the recipients of visits.

My policy was a gradual elevation of standards. We started off at a low level but have slowly screwed the standard up. On the whole I think the exercise has gone well and has improved standards of clinical practice as well as educational standards. The two go hand in hand. That is the most important thing I did as Dean, far more important than getting the exam going, which was done mainly by the Chief Examiner, Bill Trethowan.

The Deanship I found an entirely new experience, my introduction to psychiatric politics, with a small ' $p$ '. It involved chairing committees, relating to other colleges, relating to other bodies in medicine to do with education and training. I began to learn the rather labyrinthine set-up which operates in Britain in postgraduate education and how to work it.

There was a lot of hassle, understandably, from people who at the inception of the College had been 
members of the RMPA but were not entitled to be Foundation Members of the Royal College. I had to deal with this as Dean.

BB What was the criterion?

KR If you were a consultant in the National Health Service or equivalent at the inception of the College then you were entitled to Foundation Membership. There was a lot of ill feeling about this, from people who thought they were being disadvantaged. It took a lot of sorting out.

BB These were holders of non-consultant posts, at a senior level.

KR Yes. There were SHMOs and senior registrars who had to take part of the new membership exam. There were people abroad in equivocal posts difficult to equate with the British job structure. All this caused a lot of resentment, which still grumbles on.

BB It must happen at the foundation of any institution. Did you get through one round of the Approval Exercise while you were Dean?

KR One and a half really because it was a three year cycle, and I was Dean for five years, re-elected each year. Five is the limit.

BB What's going to happen now, do you think? Will the new DHSS venture into making the number of training posts equivalent to the number of anticipated vacant consultant posts result in hospitals that have been through the turmoil of being approved lose their trainees?

KR I have always seen this possibility, before the DHSS got into this act. I have taken the view that the College must be prepared to face the situation in which psychiatric hospitals and units no longer train registrars and senior registrars. They may nevertheless deliver a good service and train other personnel. On the other hand it's a mistake merely to have a few mini-Maudsleys up and down the country, for training registrars.

BB Can you be a bit more exact?

KR I can. You need a compromise situation in which you have a moderate number of centres.

BB Each one based on an undergraduate professorship?

KR Mostly.

BB You can foresee some medical schools not having professors of psychiatry.

KR I think they will all have professors of psychiatry, even the London schools in time. I was envisaging a training programme operating without necessarily too much involvement of the local university. Broadly speaking I think the training programme of the future will have a rotational element. It will have a university link and most important a 'critical mass' of postgraduate students to relate to one another, rather than at present, where three or four people can be in an isolated setting.

There is a problem which can be dealt with at senior registrar level. We see this at the Maudsley where people are trained in a hothouse atmosphere which does not, in a sense, prepare them for the hurly-burly of life in the sticks. These senior registrars as well as having time in the 'teaching centres' should be alternated to where they are less part of an academic community, where they are more likely to find themselves in three or four years time as consultants, practising the art in relative isolation. This could be catered for in the higher training level.

BB How much of your time did the Deanship take up?

KR About two days a week in London plus a lot of homework and preoccupation away from the office.

BB Good fun.

KR Oh yes, tremendous.

BB Shall we talk about distinction awards?

KR Yes.

BB What's the justification for distinction awards?

KR The justification is the goal, a stimulus, an incentive to work, to become involved in a range of things in the service. And to live in hope.

BB You have been an Adviser?

KR Yes, I was an Adviser for Wales. Now I'm the College representative on the Central Distinction Awards Committee, I hope for not much longer.

BB Do you think the system is fair?

KR Put it this way. A tremendous amount of trouble is taken to ensure that all people, using multiple criteria, are given a fair whack. Evidence is collected from a range of sources by the central body. There are a lot of fail safe arrangements for people who might be missed out. I believe that it's as fair as you can make it. Having said that, I think it is difficult to run a system like this in a rational way. To start with, if you serve on an awards committee in a region or a district, you are required to compare let us say radiologists with physicians. People's names are put forward and it is impossible to assess merit across specialities and for any one person to do this. It has become even more difficult because it is no longer just distinction but distinction and meritorious service. Meritorious service has become more important.

BB Can you explain the difference?

KR Yes. Meritorious service means what the late Sir Hector McClennan, who was a Chairman of the Central Distinction Awards Committee, termed "the heat and burden of the day". He meant the consultant who has served conscientiously and in a way which is regarded as worthy and satisfactory for a long period. They may never have hit any high spot, published any papers, achieved fame or notoriety but nevertheless done a very good job.

BB Labouring away in the hope of an award.

$K R$ Or even in the hope of helping people.

BB It was you who introduced hope of an award.

KR I know, I think that's true, but I am not saying that everybody who gets a distinction award gets it because that's been their main aim in life.

BB We were discussing whether it's fair. You discovered it is difficult to find and apply objective criteria, to 
apply a uniform standard across specialties. The solution to that is quotas of awards to each major speciality.

KR That pre-supposes the cohort of people coming into each specialty is of equal merit, which is unlikely to be true. In practice however there is a tendency for this thinking to operate, for the apparatus to say the anaesthetists are falling behind; we must see they are given better consideration. Or geographically, that the north-west of England is falling behind the south-east of England. Let us keep an eye on that. This quota thinking, when it comes to fundamentals, is wrong. But it does operate, I know that. But the figures show there are discrepancies between specialties and between regions, so it is not the sole factor.

BB Published figures are attacked along the line you have just described, of lack of equilibrium. And people accept that as a valid argument that they are not fair.

KR I don't think that's right.

BB Do you think it has a corrective influence, of making them more equal, irrespective of merit?

KR Do you mean, do I think it works like that?

BB Yes. When Bourne \& Bruggen publish their comments.

KR Yes, I do. I think it has an effect. Having said that I don't think that vitiates the main function of the award system. God knows how you could have a perfectly 'fair' system. It is difficult within a specialty and worse across specialties. But the fact that it is difficult to implement to everybody's approval, even if they approved of the idea in general, does not mean you should throw the whole thing out.

BB Do you think it is likely to persist?

KR Yes, I think so.

BB How did distinction awards start?

KR When the National Health Service was established in 1948 Aneurin Bevan agreed to this extraordinary way of making it possible, for what was then regarded as the elite of the consultants, to "have their mouths stuffed with gold".

BB That's what he was referring to?

KR Yes.

BB The merit awards were the gold?

KR Yes.

BB Is it unique?

KR I think so. I don't know of anywhere else that has it.

BB After you finished being Dean I think you stood for President.

KR Yes, and I wasn't elected. Desmond Pond was.

BB How did you feel about not being elected?

KR I think I had mixed feelings really. I was disappointed on the one hand but on the other relieved. I thought I could have another go in three years time. It gave me a breather anyway to catch up in Cardiff where my presence had been somewhat diluted while I was the
Dean. I quickly got over the disappointment and got on with what I was doing.

Three years later I put my hat in the ring again. I was uncertain about how it would go because I've learnt to be chary of taking bets on College elections. I think they are unpredictable, especially the elections involving the general membership.

BB You became President for three years. That's the limit of the office.

KR Yes.

BB Re-elected each year?

KR Yes, for two years.

BB Why was that put in the Constitution?

KR To make it possible to get rid of somebody incompetent. If it was obvious after six months that they were useless then the machinery of putting another candidate forward can be started. So far it has not been used.

BB How did you see the office of President?

KR Quite different from being Dean. The President is the Head of the College, and has to relate to other bodies, to the other Royal Colleges, the DHSS, the postgraduate education bodies such as the Council for Postgraduate Medical Education in England and Wales. I found this to be an interesting side to the work, seeing how other organisations function, how they run their affairs and also viewing the medical scene from a general platform. The Joint Consultants Committee for example. The President is a member and therefore comes into contact with the British Medical Association hierarchy. You see the political battles that go on between the organisations such as the BMA, the Colleges and the DHSS, you take part in them. Very interesting. You get something of the flavour of the balances that operate to keep the whole thing rolling along.

The President has to take a lead in matters of major importance. Thinking through the range of things I had to do there were three matters to which I had to devote a lot of energy. For example, the Mental Health Amendment Bill which eventually became the new Mental Health Act was put forward during that time. That was one thing. The arraignment of the Russian Psychiatric Society came up when the World Psychiatric Association had its meeting in Vienna in 1983. The third matter on which I spent time was organising my thoughts and taking soundings in the College about the future role of the consultant in psychiatry.

BB Did you also play a part in the day to day running of the College?

KR Yes, I certainly did. The President is concerned with everything in one sense. The Dean looks after, broadly speaking, the educational side of the College including the exam and the approval exercise. The Registrar is the chief administrator of the College. But the President copes with a range of things from basic housekeeping to enquiries from the DHSS 
which need an urgent response, or the media. It's quite a busy job, busier than the Dean's. I spent half the week at the College on average, as well as being involved when I was at home. It's a major commitment.

BB What effect does it have on your Department? This is a general question about all Royal College Presidents and their Officers I should think.

KR It's one of the interesting things about the British medical scene. You don't find them on the continent of Europe-these important organisations like Royal Colleges which rely on voluntary labour of a large number of people to run them. If you are appointed to a College office the expectations are that this takes priority, the first thing you must do, even though it's not your paid work. Inevitably what you are supposed to be doing at home suffers. As far as I was concerned I had colleagues in Cardiff who were generous and willing to take over a lot of the work of the Department. I suspect the whole thing got along very much better in my absence than it would have done if $I$ had been there, in many ways. But there is a dilemma, a sense of guilt that wherever you are you should be somewhere else.

BB What did the University think about it?

KR The University was happy about it.

BB As a distinction?

KR Yes. The Medical College and the Health Authority were happy to allow me to do the work. They saw it as bringing kudos to Cardiff and to Wales.

BB Can we talk about your experience with the Mental Health Act while you were President?

KR I had not before been involved in detailed parliamentary work and it was an eye opener. The Bill started life in the House of Lords.

BB Is that normal practice?

KR Bills sometimes start in the Lords but usually in the Commons. We were heavily involved during the Bill's passage through the Lords, lobbying peers and trying to steer the thing the way we thought it ought to go. When it went to the Commons the Government took the unusual step of setting up a Special Committee to examine the Bill in detail.

BB Who was the Minister?

KR Kenneth Clarke had the main responsibility, although Norman Fowler was Secretary of State. Kenneth Clarke attended meetings of the Special Standing Committee of the House. We gave evidence to that Committee both written and oral. I, together with some colleagues, appeared before the Committee and was grilled. I believe we modified a number of clauses in the Bill, some of which were initially a bit outrageous. Then unfortunately some things slipped passed us which caused a great deal of concern. I don't think we could have done much about some of them. For example, at a very late stage in the progress of the Bill in the Commons a Member moved an Amendment that certain treat- ments, such as psychosurgery, should be subject to a mandatory second opinion from the Mental Health Act Commission, even if the patient was "not liable to be detained". That was put forward from the floor of the House and to my horror was accepted straight away by Kenneth Clarke for the Government, to the amazement, I believe, of his advisers who were in the House. That was a major setback. It meant that the consultant and the patient together no longer had the right to work out between themselves what was the best treatment, even though the patient was informal. The overriding feature was that under that part of the Act the Minister had the power to include other treatments if he wished.

It seemed to me that we were in danger of a situation where many of our treatments could be subject to mandatory second opinions, in out-patients or even in general practice, because the Act applies to all mentally disordered persons. We tried hard to get this overturned when the Bill went back to the Lords. With their traditional good sense the passage of the Bill in Scotland did not include that clause. In Scotland there are no such restrictions on the use of psychosurgery. I wondered whether we would have clinics in Gretna Green.

The Mental Health Act Commission created by the Act we had asked for. I am not sure it has worked quite as we would have wanted. The Commission is an unwieldy body containing some people who I think have very little appreciation of the realities of psychiatric work. They take an impractical, ideologically-based view of what should happen. It is still too early to say how that Act is going to work out in practice.

There is a powerful anti-psychiatric feeling among many Members of Parliament. I think it might have been part of a general anti-medical feeling, but it was clear and it is worrying. It alerted me to our standing and our image in the public mind. I've been preoccupied with it ever since and I voiced my concern in my Presidential Address to the College. ${ }^{6}$ We are at risk of being reduced because of misconceptions about our role and our function by the uninformed.

BB Do you understand what led up to the new legislation?

KR There were anxieties fuelled by the enquiries and scandals which occurred in mental hospitals and mental deficiency hospitals. The feeling had grown that detained patients were not adequately protected by the 1959 Act. A major factor was to improve the safeguards before detaining patients. The other element which the College was sympathetic to was to find an inspectorate to keep an eye on what was happening in psychiatric hospital practice. Since the dissolution of the Board of Control under the 1959 Act that had not been happening except through the Health Advisory Service, which does not have strong teeth. 
BB The mood of parliament and of influential people in the period leading up to this Act seems different to their mood leading up to the 1959 Act.

KR Yes. The 1959 Act was in keeping with the spirit of that time. There had been an extraordinary revolution in psychiatric practice particularly in hospitals in the 1950s, the unlocking of doors, the discharge of large numbers of patients and the great increase in the numbers of voluntary patients. There was a feeling of optimism, of a revolution if you like, in psychiatric practice, reflected in the 1959 Act. A good example is the de-designation of mental hospitals. Before 1959 mental hospitals were designated by Act of Parliament as places which could receive detained patients. It was not possible to have detained patients in other hospitals. The 1959 Act removed the distinction and it was then possible to have detained patients in any hospital willing to take them.

BB What went wrong do you think, if anything did go wrong, to produce this feeling? Did psychiatrists overplay their hand? Or was it a direct outcome of the scandals, for which scapegoats had to be found for the underfunding which lay behind?

KR It's a complex question and I don't know the answer. There is, I believe, a general anti-professional, antimedical movement, and anti-scientific also: don't trust professionals. That view was fuelled by emotion coming from the civil liberties lobbies. So the whole thing became transformed into an issue of building in safeguards. It's not good enough to let the doctors get on with it, we must have clearly defined safeguards under an Act, and bring in other people who are not psychiatrists, to keep an eye on them and take part in the process of detention, approval of certain treatments and so on. It's a downgrading of the professional role.

BB Without doubt, in practice.

KR I believe this is potentially bad for clinical practice, and for patients. I also think it has been seized upon by organisations which involve other professionals in the health field, for their own aggrandisement.

BB What are you thinking of?

KR I'm speaking generally, because the majority of people in these professional groups would not work in this way. But there are elements in, let us say, social work, in clinical psychology which have chosen to harness this energy for their professional advancement; the upgrading, if you like, of their activities in the mental health field. Sometimes this has been done rather unscrupulously.

BB Do you not think that ultimately the problem lies in the comparative lack of technical skill in the psychiatrists?

KR I don't agree with that view. I had the scales pulled from my eyes when I got into epidemiology and saw physicians in action. For example, we regard X-rays as a precise tool. I was involved as a spectator in some systematic evaluation of X-ray reading, on a big scale. I was amazed by the amount of observer variation and bias in the reading of $\mathrm{X}$-rays. When I worked in clinical pathology I had always thought of the laboratory side of pathology as an exact science. There was a test used for estimating globulin in cerebro-spinal fluid, the Pandy Test. You put something into a sample of CSF and it went milky. The globulin was determined by comparing this milkiness with a standard set of scales or tubes with variable milkiness. This was about the most imprecise thing you could imagine and absurdly vague in practice. Some of this technical precision is actually pseudo. Robert Platt, that master clinician, taught the most important element in making a diagnosis was the history, and that is notoriously imprecise. The high technology side of medicine, though I applaud it in many ways, must not blind us to the fact that precision can be practised by psychiatrists just as well as it can be by physicians and surgeons. The ability of psychiatrists to alter the course of illness is actually good-high in many cases. If you look at some of the terrible problems of general medicine, which really can't be cured even by a high-powered technology, we are not so badly off.

BB Did you find MPs aggressively against psychiatry?

KR Yes. Many of them.

BB And the reverse?

KR Yes. Some were sympathetic.

BB As energetically as the others were against?

KR Yes, especially in the House of Lords. A number of peers took a great deal of trouble to find out and present a point of view which was balanced and reasonable. I was impressed by the standard of debate in the House of Lords, much better than the Commons. You might say they had more time.

BB You mentioned the Russians.

KR I had been a member of the College Special Committee on the Political Abuse of Psychiatry for some years. When I first joined that committee I was a sceptic. I didn't believe it was an important problem. I thought a lot of the stuff being put about was propaganda and disinformation.

BB Especially about the Soviets?

KR Yes. But when I looked at the data I decided it was a real problem and a very worrying one. When I became President $I$ regarded it as a major issue for the College and myself too. The Russians, by incarcerating dissidents in mental hospitals for no better reason than their speaking out against the Soviet state, prostituted our discipline, something which had to be opposed in the strongest possible way. To try, and perhaps secure, the release of these unfortunate people would right a wrong and remove a major blot on our professional image. I spent much time on this matter and became involved in the movement through the World Psychiatric Association to find out what was going on in the 
USSR. The World Congress of the Association, which happens every six years, took place in Vienna in the penultimate year of my presidency. The College mounted a strong campaign to arraign the Russian Psychiatric Society.

BB Were the other WPA member countries allied with you?

KR Yes.

BB All of them?

KR No, not all. Some were much opposed. The American Psychiatric Association was our principal ally, and some of the European psychiatric societies. When the Motion was put in the pipeline to be debated in Vienna, which would have led to the expulsion of the Russian Psychiatric Society from the WPA, the Russians pre-empted us and resigned from the Association a few months before the meeting. We went ahead nevertheless and had a debate at the Congress, a very acrimonious debate. There were a number of Russian supporters even though the Soviets weren't there themselves. Attempts were made to have the whole thing set aside. But our resolution, re-worded at the meeting, was passed by a substantial majority. In effect it criticised the USSR for what was happening, at the same time saying that the WPA would welcome the Russian Society back into the fold when evidence was clear that the offending practices had stopped. We made our point. Since then things have happened in the USSR with the 'glasnost' policy of $\mathrm{Mr}$ Gorbachov, the release of some prominent dissidents which we had campaigned for, including Anatoly Koryagin. There is evidence that incarcerating dissidents has eased up, although still going on. We have to keep pushing.

BB It is largely a political rather than a clinical matter. Could Russian psychiatrists stop it?

KR No, I don't think they could. The number of psychiastrists involved is small and most are well up in the hierarchy of Soviet psychiatry. I don't think they would desist without a clear directive from above.

BB You see this issue as important for the reputation of psychiatry outside Russia? Even more important than what was happening to the dissidents.

KR Both. As far as the College was concerned we were not trying to tell the Russians how to deal with dissidents, but we were saying you must not regard them as mentally ill when they are not. You must not give them injections of psychoactive drugs and lock them up in mental hospitals for years for saying things which the Soviet Government does not like.

BB Do you think the involved people in the Soviet Union knew what they were doing, or do you think that they believed that dissidents were mentally ill because of a different view of what is mental illness?

KR I believe some knew the truth but continued to operate the system. Others I'm not sure about. They may have persuaded themselves that anyone who has the temerity to speak out in public against Soviet policy was ipso facto insane. Even if that were true it would not justify committing a person to a mental hospital for years or to use these powerful treatments. Under the Soviet constitution, in theory, there is the right of free speech. The dissidents were not a danger to themselves or to anyone else in any ordinary sense of the word.

BB Shall we leave the Soviets? The third matter that you felt was important while you were President was the role of the consultant.

KR Yes, I did. The business of the Mental Health Act and anti-psychiatric feeling seemed to be knocking the image of the consultant psychiatrist which led me to think hard about this question. Especially the authority of the consultant in modern psychiatric practice, particularly in the multi-disciplinary team. The feeling that the doctor should be one member, with no special authority, and accept corporate decisions for managing patients.

I tackled this by writing a paper on the future of the consultant using a number of headings. ${ }^{7}$ I circulated it through the College to Divisions and Sections for comments. I then reformulated the paper as recommendations to Council. Council debated these issues and broadly speaking supported what I recommended. Essentially they endorsed a policy statement made some years earlier by the College on the role of the consultant, that the consultant should be primarily responsible for the care of patients, should have the major responsibility for making decisions, certainly with advice and help from other professional groups, but that there should be no question about where the prime responsibility lay.

There were other aspects to the paper. For example, the relationship between consultants and general practitioners and the question for instance as to whether it was desirable to have direct access to consultants, walk-in clinics, this type of thing. On the whole the Council was against them. It took the view that the general practitioner should be the central figure in medical practice and the consultant, broadly speaking, should operate through the general practitioner wherever possible.

BB Why do you think the consultant's position was threatened?

KR Tosome extent because of indecision and uncertainty on the part of consultants themselves. Some consultants became unsure as to whether they did have special skills, whether they did have a particular expertise in psychiatry in comparison with, let's say, psychologists and social workers. This is in part a result of the erosion of confidence among consultants which has been one of the products of the antipsychiatric feeling. They have become unsure of themselves listening to critics. Many of these consultants, perhaps working in isolation, were persuaded there was nothing very special about being a doctor 
in psychiatry. One should just be a member of the investigation and treatment committee. That is a recipe for disaster.

BB From the patient's point of view?

KR Yes. Language is one of the problems we have to cope with. For example, people say "Well, you know, you shouldn't rely on the medical model, the medical model is very narrow, and a very partial way of looking at problems". If you accept those words then you are accepting a false statement because medicine in general, and psychiatry as a branch of medicine, is actually a broad subject. The medical man or woman by virtue of the training they have received are able to draw on a biological standpoint, a psychological standpoint and a social standpoint, all of which should come together in the assessment of the clinical problem. The imputation of the term 'medical model' is that it is to do only with organic factors, drugs and a mechanistic way of looking at patients. This is quite wrong. The medical model, as I define it, brings in all angles from the biological to the social. A good doctor uses a complex, elaborate point of view, in assessing a clinical problem. That is the medical model in my opinion. A unique perspective, the product of a long training.

BB By unique you mean it is not held by any other profession involved in treating patients?

KR Yes. It is a broader perspective than that of any other professional group in the health field. By virtue of that the doctor, the psychiatrist, should hold pride of place in decision making about patients. It's not a popular view.

BB Why doesn't everybody believe it?

KR Why don't all psychiatrists believe it?

BB The other professional groups.

KR I think if they believe that they would feel their own professional development was being imperilled. Bear in mind that clinical psychology and social work are young professions by comparison with that of medicine. They have to make their way in the world, build up their image and their standing. To do that they must make territorial claims which, inevitably, will be at the expense of existing professions.

When developing something new you tend to push hard and perhaps overplay it. Their contributions are great, but they have to be fitted into a scheme of management for patients where the doctor, the psychiatrist, must be the key figure in making decisions.

BB How is the confidence of the doctor to be improved?

KR It is a major function of the College. The College has a duty to promote this point of view through its educational programmes, through meetings and through conferences; to infuse a sense of confidence and a proper appreciation of the doctor's ability and skill to take a leading part in the management of the patient. The College must maintain a sense of integration, of family if you like, in our profession. Because of the complexity of psychiatric medicine, and the many specialities within psychiatry, so many orientations, there is a factious tendency which could be dangerous. The College is the only organisation in Britain which has the power, the resources and, I hope, the will to keep the family together. There have been times when I thought we were going to lose a chunk of our brethren, that certain sections might hive off. I won't go into detail but it was averted.

BB Right at the outset of the College? But it's not a problem now is it?

KR I don't think so. It's something to be watched and pre-empted if it looks like happening.

BB So you had three years as President and you seemed to have enjoyed them.

KR Yes, I did, except that during my penultimate year I wasn't well. I developed an illness which, because I chose to have the treatment in London, meant paradoxically that I spent rather more time in the College than I otherwise would have. Even so it was quite a nuisance during that last year.

I had been having symptoms of prostatism for some years and put off doing anything about it, couldn't really be bothered. Eventually $I$ had it investigated because it became difficult. I went in for what I thought would be a routine prostatectomy and it turned out malignant. Quite unexpected. I then had to have radiotherapy, which wasn't too bad in itself, but it meant going every day or so to hospital, so I had to cut down my activities. But because I was staying in London I was able to carry on at the College.

The illness itself caused me to see life in different terms. It's amazing how when you develop a potentially fatal illness you take stock of the situation and paradoxically savour certain aspects of life more keenly than before. That certainly happened with $m e$. In other ways it was a major nuisance. I haven't often been ill but whenever I have been ill, particularly if I have had to have treatment, I have regarded the experience as one to be treasured from the professional point of view. The experience of illness in oneself as a doctor is beneficial, or can be, in enhancing one's empathy and sensitivity to illness in patients, making one more aware of the anxieties, the immense dependence which patients develop. And the importance of a sensitive, careful response on the part of the clinician. And not only the clinician but all the staff who are concerned with you. From that point of view it had its positive side.

Eventually, some two years after when I got secondaries, I decided to retire from the Chair of Psychiatry at Cardiff. I took the view that with the form of malignancy I had the pace of life was going to be important in influencing prognosis and I wanted to cut down my activities to a large degree. 
As it has worked out, with further treatment, and perhaps because of a different way of life, I'm not feeling at all bad at the present time.

BB Do you think the prognosis would have been affected adversely if you had remained at work?

KR I think so. The endocrine-sensitive cancers, particularly, are, I believe, likely to be influenced by the general state of vitality, as well as by outlook. There is some evidence on breast cancer outcome to support the idea that mental attitude affects survival. This could well be true of prostatic disease. It is no doubt mediated by hormonal influences.

BB Did you have a sense of anger, having been given this disease?

KR More of frustration. Perhaps that's linked to anger. I did feel frustrated by having to undergo all the treatment and waste a lot of time going to hospitals and seeing doctors. I also felt irritated. When I went to Vienna to represent the College's view on the Russian affair I was partly incapacitated by symptoms. My experience of Vienna was largely as a map of the public lavatories in the city to which I could have urgent recourse. I remember sitting through the meetings and occasionally having to nip out, being careful not to do so when a crucial vote was about to be taken. I wondered how much of the British Empire had been lost through a prostatic absence at a crucial time.

BB Perhaps this is an appropriate time to move on to a different kind of sick doctor.

KR You're thinking of my interest in sick doctors and the development of the National Counselling Service. That was prompted by my work on the first Merrison Committee established to look at the regulation of the medical profession. This Committee which reported in 1975 looked at the function of the General Medical Council in respect of sick doctors. At the time the GMC could only deal with alcoholic doctors, and other doctors failing professionally through illness, by its disciplinary procedures. One of the outcomes of Merrison was the new Medical Act which made it possible for the GMC to set up a Health Committee, a more humane, rational way to deal with doctors who failed through illness. I was impressed by the evidence we received in that committee about the extent of the problem of sick doctors and it led me to try to think of ways and means in which we could develop machinery to help doctors before they had to be picked up by the GMC. An opportunity arose when the Association of Anaesthetists wanted to set up a scheme for their own members and our College helped them with that.

BB It's mainly a problem of addiction.

KR With the anaesthetists yes, drugs and alcohol. But later on it seemed appropriate to broaden the service. Initiatives were taken by Sir John Walton for the General Medical Council and by Mr Tony
Grabham for the British Medical Association. I was asked to set up a national service with a small management committee, to be autonomous and independent. This service opened in October of 1985 and covers the United Kingdom. It has a network of advisers and counsellors willing to help doctors. A number of things struck me forcibly about this service. The first is the way in which the profession has been willing to help. Of some 300 people that I have approached to help not one has refused, a remarkable tribute to the profession's willingness to look after its own.

BB Are you talking of 300 psychiatrists?

KR No, doctors of all kinds. The second is that so far the scheme has worked smoothly. We're running a referral rate of about 10 new cases a month. Its confidential and private so one doesn't know what's happening to the patients. So far there have been no major hiccups. I hope it is doing some good but I don't know for sure.

BB You act as a central referring agency?

KR Yes, we have a hotline telephone in London which is manned by doctors. I act as a co-ordinator with a small management committee. The DHSS pays, although it doesn't cost much.

BB The Service finds a doctor to care for the referred doctor?

KR Yes.

BB The Service doesn't know who the referred doctor is?

KR No, the central body.doesn't know who the referred doctor is. The purpose is for a worried colleague of a sick doctor to get in touch with the scheme. They can then be linked with an adviser who will try to approach the sick doctor and persuade him/her to accept help. A fifth to a quarter of the referrals are sick doctors themselves ringing up saying they would like help, but they don't want to consult local colleagues. It's easy for us to put them in touch with someone outside their own region.

BB Do you mean a worried colleague who obtained the name of an adviser would then go to the adviser, share his worry and the adviser would then, as it were, unilaterally approach the object of worry?

KR Yes, a delicate undertaking.

BB It would be interesting to know the outcome, wouldn't it? Is there a way of finding out?

KR I had a meeting of national advisers recently in London. It was to some extent impressionistic data which came out, but certainly there are cases taken on board as a result of this approach, but one doesn't know the ultimate outcome. It is going to be difficult to evaluate.

BB Would you like to say something about your views on the future of psychiatry?

KR I have an optimistic view, in one sense. I believe psychiatry as a profession will continue to exist and tackle the problems of mental illness for a long time to come. I am more sceptical about major 
breakthroughs in the diagnosis and treatment of mental disorders. There will be developments, particularly in dementia. But the crystal ball is dark in predicting the changing limits of psychiatric involvement in human affairs over the next decade or two. This is an important issue in which there could be useful research jointly between psychiatrists and general practitioners. General practitioners do the bulk of psychiatric work in this country and are often unsure about the proper limits of their involvement in human misery, unhappiness and discontent. The limits of psychiatry are constantly refined in terms of values and expectations of the profession and of the general population.

BB Is distress a medical matter?

KR For the most part, no. But distress may be the cause or consequence of some disturbance of psychological or physical function where a doctor may be able to help. There is a risk as happened in the United States in the 1950s that psychiatry becomes too extended, proclaiming its interest in territory which is well beyond its proper scope. Its a matter of fine judgement as to where these limits should be set. And they do keep on shifting. We should be more aware of limit setting, if you like, and look at it from an operational point of view.

BB What do you mean by that?
KR Look at it from the point of view of the validity of our power to intervene effectively in situations and in ways which other professions or lay people cannot.

ACKNOWLEDGEMENT

Mrs Sheila Dickinson transcribed the interview and prepared the manuscript.

\section{REFERENCES}

${ }^{1}$ Anderson, E. W. \& Rawnsley, K. (1954) Clinical studies of lysergic acid diethylamide. Monatsschrift für Psychiatrie und Neureologie, 128, 38-55.

${ }^{2}$ Leighton, A. H. (1959) My Name is Legion. New York: Basic Books.

${ }^{3}$ Srole, L., Langner, T. S., Michael, S. T., Opler, M. K. \& RenNIE, T. A. C. (1962). Mental Health in the Metropolis. New York: McGraw-Hill.

${ }^{4}$ Ingham, J. G., Rawnsley, K. \& Hughes, D. (1972) Psychiatric disorder and its declaration in contrasting areas of South Wales. Psychological Medicine, 2, 281-292.

${ }^{5}$ RAWNSLEY, K. \& LOUDON, J. B. (1964) Epidemiology of mental disorder in a closed community. British Journal of Psychiatry. $110,830-839$.

6_ (1984) Psychiatry in jeopardy. British Journal of Psychiatry. 145, 573-578.

7_ (1984) The future of the consultant in psychiatry. Bulletin of the Royal College of Psychiatrists, 8, 122-126. 